\title{
Uma pesquisa-ação sobre o desenvolvimento do pensamento computacional com crianças
}

\author{
Mauro Marcelo Mattos, Luciana P. de Araújo Kohler, Heitor U. C. Silveira, \\ Lucas Eduardo Schlögl, Gian Carlo Giovanella, Bruno F. F. Santos, \\ Leonardo Fronza, Fabrícia Durieux Zucco, Nelson Hein, \\ Gabriel Castellani de Oliveira, Karina Zendron da Cunha, Andreza Sartori \\ ${ }^{1}$ Laboratório de Desenvolvimento e Transferência de Tecnologia (LDTT) \\ Universidade Regional de Blumenal (FURB) - Blumenau, SC - Brasil \\ $\{$ mattos, lpa\} @ furb.br
}

\begin{abstract}
This paper presents an action-consultation with children of the 3rd year and 4th year of elementary school in a public school. The purpose of action research is to support the development of computational thinking in this age group. To do this, we use the platform that use programming basic concepts and playful and intuitive exercises like a game. At the beginning of the study, an exercise was applied with the objective of assessing the students' cognitive and reasoning capacity. In the end of our study, we can observe a significative evolution in many aspects, evidencing that the platform can be a util tool to cognitive development in this age group.
\end{abstract}

Resumo. Este artigo apresenta uma pesquisa-ação realizada com crianças do $3^{o}$ e $4^{o}$ ano do ensino fundamental de uma escola pública. O objetivo da pesquisa-ação é auxiliar no desenvolvimento do pensamento computacional de crianças nessa faixa etária. Para isso, utilizou-se uma plataforma que faz uso de conceitos básicos da programação aplicados à diversos exercícios lúdicos e intuitivos em forma de jogo. No início do estudo, um exercício foi aplicado com o objetivo de avaliar a capacidade cognitiva e de raciocínio dos alunos. Ao final do processo, pode-se observar uma evolução significativa em ambos os aspectos, evidenciando que a plataforma pode ser uma ferramenta útil no desenvolvimento cognitivo de criancas nesta faixa etária.

\section{Introdução}

Segundo [Raabe et al. 2017], a computação é uma ciência que investiga a resolução de problemas, proporciona a criação de um mundo novo e muda radicalmente o comportamento da sociedade. Dessa forma, pode-se afirmar que aprendendo computação é mais fácil de resolver problemas cotidianos, além de criar formas novas de pensar e agir. A necessidade em resolver problemas está presente na vida do ser humano desde o seu nascimento, uma vez que necessita encontrar uma forma de se alimentar e interagir com os familiares, por exemplo. Essa necessidade vem crescendo a medida em que o indivíduo evolui, sendo que alguns possuem mais dificuldades em compreender, raciocinar sobre o que está sendo proposto em determinados problemas ou sobre o que está enfrentando, apresentando uma dificuldade relacionada ao raciocínio lógico [Scolari and Bernardi 2007].

De modo a contribuir com o desenvolvimento do raciocínio lógico e outras habilidades computacionais, a Sociedade Brasileira de Computação (SBC) propõe que a 
VII Congresso Brasileiro de Informática na Educação (CBIE 2018)

Anais do XXIV Workshop de Informática na Escola (WIE 2018)

Computação seja inserida na grade do ensino básico até o ensino médio, incluindo as escolas públicas [Raabe et al. 2017]. Contribuindo para que a proposta seja cumprida, a partir de 2017, um projeto de extensão vem sendo utilizado para desenvolver habilidades de pensamento computacional com alunos de terceiro e quarto anos do ensino fundamental de uma escola estadual da região. Os conceitos trabalhados envolvem: desafios de raciocínio lógico e sequencial. A plataforma utilizada ampliou as possibilidades de uma plataforma mais antiga que vem sendo utilizada já há 10 anos no apoio ao ensino de programação de computadores em cursos de graduação em Ciência da Computação e Sistemas de Informação. Na graduação o foco é o desenvolvimento de habilidades de programação Java utilizando conceitos de programação orientada a objetos. O ambiente de desenvolvimento é baseado em Netbeans ou Eclipse e a interface busca introduzir os ambientes tradicionais de desenvolvimento de software aos acadêmicos. Já a versão utilizada no ensino fundamental possui uma interface lúdica tendo como objetivo conduzir as crianças para um ambiente de jogos de computador no qual os desafios vão tendo sua complexidade aumentada a medida em que as fases vão sendo vencidas. A medida em que avança nas fases, a criança começa a ter contato com conceitos básicos de programação e algumas regras sintáticas muito simples.

O projeto buscou identificar como atividades de programação de computadores pode afetar positivamente o desenvolvimento de habilidades de raciocínio lógico e tomada de decisões no cotidiano das crianças através de uma pesquisa-ação realizada com aproximadamente 40 estudantes com idades entre 8 e 10 anos. O período de acompanhamento foi de 8 meses.

O presente artigo é dividido da seguinte forma: a Seção 2 apresenta as diretrizes da programação recomendas pela SBC a serem utilizadas no ensino da Computação para a educação básica; a Seção 3 aborda o aperfeiçoamento e desenvolvimento da ferramenta de computador; a Seção 4 descreve a pesquisa-ação realizada, apresentando também a avaliação aplicada; e, por fim, a Seção 5 discorre a respeito dos resultados alcançados e faz projeções para trabalhos futuros.

\section{Diretrizes da programação recomendadas pela SBC}

Segundo [Raabe et al. 2017], os conhecimentos da área da computação são divididos em três eixos, sendo: o pensamento computacional, o mundo digital e a cultura digital. $\mathrm{O}$ pensamento computacional está relacionado a análise da informação, abstração da realidade e automatização de soluções. Por sua vez, o mundo digital relaciona-se a codificação, processamento e distribuição do código-fonte e/ou material produzido. Por fim, a cultura digital diz respeito a fluência digital, ética digital, computação e sociedade. Com base nestes três pilares da computação, o grupo de trabalho da SBC coordenado por [Raabe et al. 2017] propôs as habilidades que devem ser trabalhadas com os alunos da educação infantil, ensino fundamental e médio relacionados a computação.

Com relação ao pensamento computacional, conforme o documento proposto pela SBC por [Raabe et al. 2017], na educação infantil deve-se trabalhar com habilidades voltadas a compreensão de problemas, identificação de sequência de passos, representação dos passos de forma relacionada e organizada, passos relacionados a movimentação de corpo e trajetos espaciais. No ensino fundamental do $1^{\circ}$ ao $5^{\circ}$ ano, as habilidades relacionadas ao pensamento computacional são voltadas a abstração de experiências concretas 
VII Congresso Brasileiro de Informática na Educação (CBIE 2018)

Anais do XXIV Workshop de Informática na Escola (WIE 2018)

descritas através de dados e listas, identificação de estruturas condicionais e de repetição, uso de linguagens lúdicas para representação de algoritmos, compreensão sobre como decompor um problema para soluciona-lo em pedaços. No ensino fundamental do $6^{\circ}$ ao $9^{\circ}$ ano a recomendação é que seja introduzida a linguagem de programação nativa para representação de dados e processos, além da formalização dos conceitos em estruturas de dados, uso de recursões e generalizações. Por fim, para o ensino médio é recomendada a realização de projetos integrados a áreas de conhecimento curriculares, usando diferentes plataformas e linguagens de programação. Além disso, é recomendada a análise do custo das implementações realizadas, argumentar sobre a correção dos algoritmos e compreender os limites da programação de modo a perceber o que pode ou não ser automatizado e mecanizado [Raabe et al. 2017]. Tendo essa documentação como guia, o trabalho tem como foco atingir o público alvo do ensino fundamental fases iniciais entre $1^{\circ}$ e $5^{\circ}$ ano, aplicando as práticas recomendadas pela equipe da SBC.

\section{Desenvolvimento da plataforma}

A plataforma utilizada na graduação apresenta-se na forma de um tabuleiro onde o aluno interage com obstáculos para cumprir os desafios propostos. O personagem principal é um pequeno robô e para movimenta-lo o acadêmico deve fazer uso dos recursos de programação em Java para implementar a lógica do método inteligência do robô. Um exemplo pode ser visto na Figura 1, em que o robô deve chegar até o Tesouro. Para que isso ocorra, é necessário utilizar comandos Java em conjunto com comandos similares à fala humana, que são disponibilizados pelo jogo para chegar ao objetivo. Para conseguir realizar o exercício, o acadêmico deve criar uma classe Java, importar os pacotes necessários para o jogo e associar essa classe criada com um exercício através de linhas de comando. $\mathrm{Na}$ Figura 2 pode-se visualizar um exemplo do código-fonte implementado na classe Java.

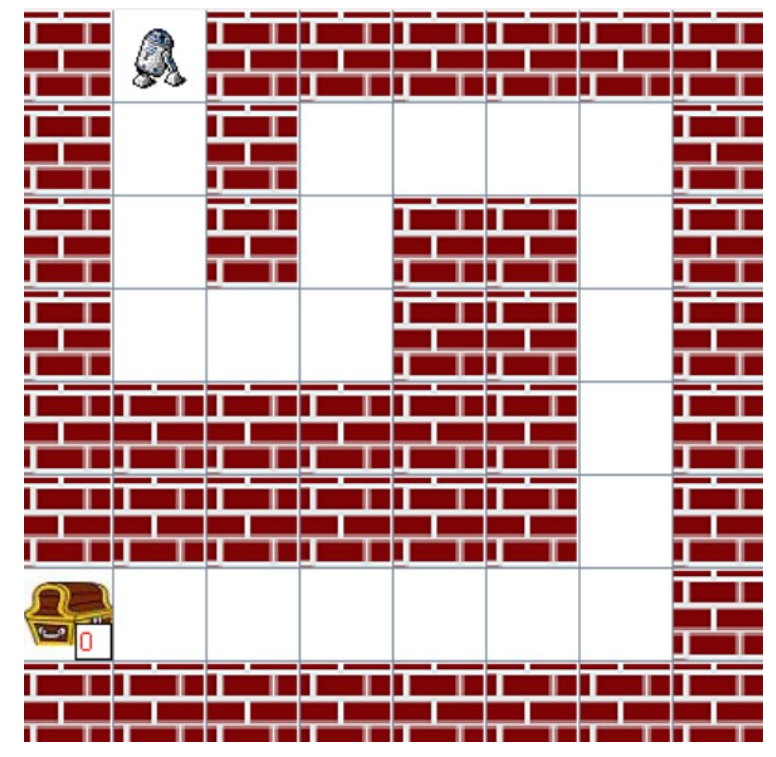

Figura 1. Exemplo de uma das telas do jogo

O processo de ambientação das crianças com os conceitos subliminares de funcionamento da plataforma é introduzido através de um jogo de tabuleiro com cartas que contem as regras básicas e as restrições de funcionamento do ambiente. Esta estratégia 
VII Congresso Brasileiro de Informática na Educação (CBIE 2018)

Anais do XXIV Workshop de Informática na Escola (WIE 2018)

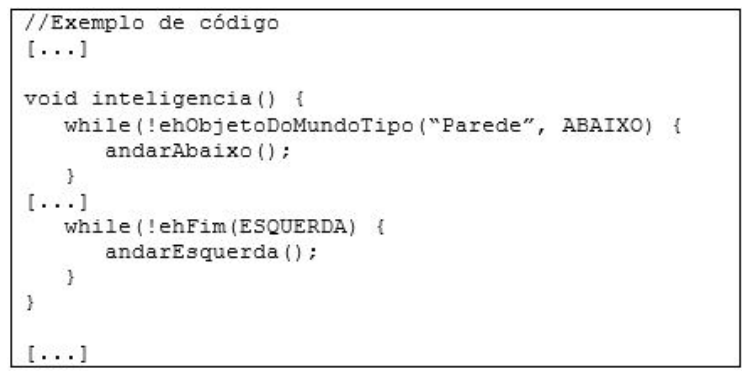

Figura 2. Exemplo do método inteligência do robo

possibilita uma migração natural do jogo em tabuleiro para o ambiente em computador. As cartas possuem os movimentos permitidos para movimentar os personagens no tabuleiro e estes movimentos mapeiam para os comandos que posteriormente deverão ser emitidos para que o robô movimente-se pelo ambiente.

Com o objetivo de facilitar o processo de aprendizagem das crianças, foram realizadas adaptações na interface visando torna-la mais agradável e lúdica [Schlogl et al. 2017]. Sendo assim, aproveitou-se grande parte do back-end, que contém métodos de interação com objetos e movimentação de mundo, para dedicar-se à desvinculação do jogo de uma linguagem de programação e também para uma adaptação para crianças na interface gráfica.

Ao entrar no jogo desenvolvido, a criança visualiza opções dividias por grau de dificuldade, incluindo fácil, médio e difícil. Para ambientar o aluno ao jogo, no nível fácil é permitido que ele resolva os exercícios com o uso das setas do teclado, obtendo, no final, a lista de comandos que foram realizados. Na Figura 3 é possível visualizar o cenário em (A) e o código resultante em (B) do exercício concluído. Caso o exercício seja de dificuldade média ou superior, a Figura 3 (B) também exemplifica o código que precisaria ser desenvolvido pelo aluno.

Nos outros níveis de dificuldade, a opção de resolver por meio do teclado é bloqueada e o aluno deve chegar ao objetivo por meio das linhas de comando, que são similares à fala humana. Um dos principais aspectos positivos desse módulo é que a criação de laços de repetição é facilitada pela interface, que disponibiliza uma lista de verificações que podem ser feitas e o aluno só completa com os comandos de andar. A parte do laço de repetição pode ser visto na Figura 3 (C), exibindo onde as verificações podem ser realizadas.

Além de comandos de programação, o jogo também verifica operações inválidas causadas pela má programação do algoritmo, como tentar andar sobre um objeto bloqueado ou sair do mundo.

\section{Pesquisa-ação}

A pesquisa-ação foi estruturada conforme definido por [Davison et al. 2004] (Figura 4), sendo composta pelas seguintes etapas: diagnosticar, planejar ação, intervir, avaliar e refletir. Ao final de cada ciclo, pode-se retornar a primeira etapa com o objetivo de reavaliar o diagnóstico e iniciar o novo ciclo da pesquisa.

Os ciclos da pesquisa envolveram 40 crianças entre 8 e 10 anos, das terceiras e 
VII Congresso Brasileiro de Informática na Educação (CBIE 2018)

Anais do XXIV Workshop de Informática na Escola (WIE 2018)

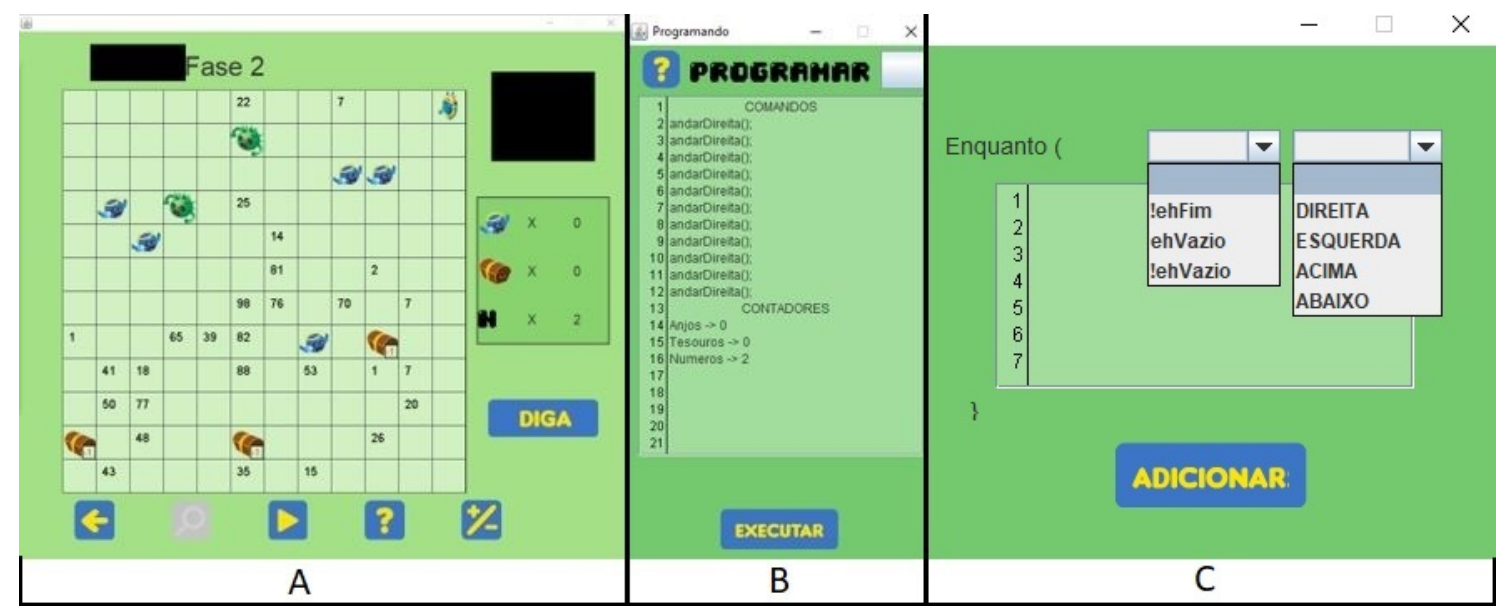

Figura 3. A: Exemplo de mundo, B: Console Programar, C: Painel do Enquanto

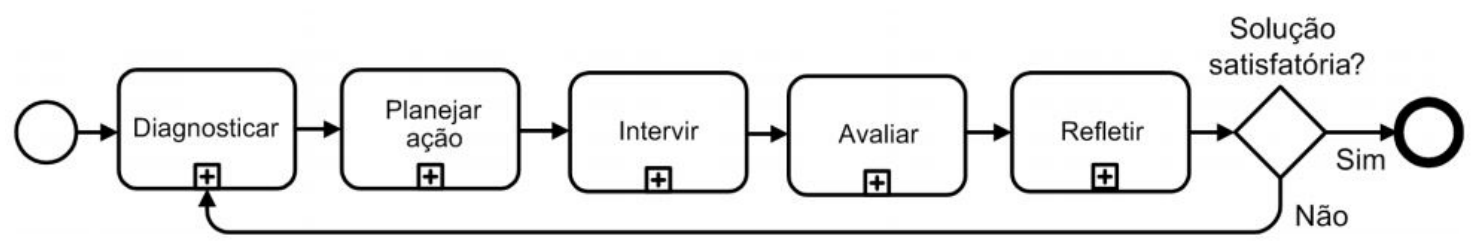

Figura 4. Ciclos de pesquisa-ação

[Davison et al. 2004]

quartas séries do ensino fundamental. Os encontros aconteceram durante um período de oito meses, de abril a novembro de 2017 , todas as segundas-feiras, com duração de uma hora. Ao todo foram concluídos 22 ciclos de pesquisa-ação com cada uma das turmas, resultando 44 ciclos completos. Apesar de algumas dessas crianças não possuírem computador em suas casas, todas elas já tinham familiaridade com o uso do computador e sabiam digitar. Essa afirmação foi obtida através de uma entrevista coletiva realizada com elas.

Para melhor compreensão da metodologia utilizada nos ciclos, o mesmo segue relatado a seguir, sendo este correspondente ao primeiro ciclo da pesquisa-ação:

1. Diagnosticar: o primeiro ciclo teve como objetivo verificar se o raciocínio lógico evoluiu com a prática da programaçãopara. Para isso, o diagnóstico inicial foi realizado com uma atividade prática sem o uso do computador, envolvendo conceitos a respeito do pensamento computacional para que fosse possível avaliar, no final do primeiro ciclo;

2. Planejar: o planejamento ocorreu de forma interdisciplinar, juntamente com a professora responsável pelas turmas. Nesse primeiro ciclo, planejou-se um jogo de tabuleiro envolvendo conteúdos de Geografia que eram trabalhados nas aulas, como a rosa dos ventos e mapas do estado e da cidade. Dessa forma, após o planejamento foi construído um tabuleiro com um mapa das cidades do estado (Figura 5), cartas correspondentes a passos (andar leste, andar oeste, andar norte e andar sul) e um exercício. O exercício orientava a criança a sair da cidade A e chegar até a cidade $\mathrm{B}$, porém para atingir o destino ela não poderia passar pelas cidades C, D e E, por exemplo. Para resolver o exercício, cada criança precisava 
VII Congresso Brasileiro de Informática na Educação (CBIE 2018)

Anais do XXIV Workshop de Informática na Escola (WIE 2018)

formar o caminho para chegar até a cidade de destino utilizando as cartas com os passos (Figura 6). Dessa forma, sem que elas soubessem, a lógica sequencial estava sendo introduzida e testada;

3. Intervir: a intervenção ocorreu nas duas turmas, de modo que as crianças trabalharam em grupos de 4 alunos. As atividades ocorreram durante uma hora, na qual cada grupo foi acompanhado de um instrutor para que este pudesse anotar o que estava acontecendo e tirar as dúvidas durante o jogo. O instrutor explicava a atividade para o grupo e então instruia como proceder com o jogo, porém não auxiliava na escolha da jogada. Ao todo, cada equipe realizou aproximadamente 4 rodadas do jogo, com objetivos diferenciados;

4. Avaliar: durante essa primeira ação realizada, percebeu-se uma dificuldade com relação ao entendimento da sequência de passos. Para as crianças, bastava sair da cidade $\mathrm{A}$ e chegar à cidade $\mathrm{B}$, sem se preocupar com o menor caminho, com obstáculos ou com outras variáveis existentes. Ainda, algumas delas, ao executar a sequência de passos, passavam duas vezes pela mesma célula do tabuleiro, sem haver essa necessidade. Essa avaliação foi realizada através da observação direta durante a intervenção. Por meio da observação direta, anotou-se as jogadas das crianças para uma análise posterior;

5. Refletir: na reflexão, percebeu-se a necessidade de iniciar intervindo as jogadas das crianças e apresentando-lhes quando a jogada era otimizada e quando não era, de modo que no decorrer das próximas jogadas elas pudessem compreender e tomar essa decisão por conta própria. Esse primeiro ciclo foi importante, pois antes de ir ao jogo de computador, achou-se necessário que as crianças compreendessem o processo realizado pelo computador, com o objetivo de se preocuparem na otimização do código-fonte.

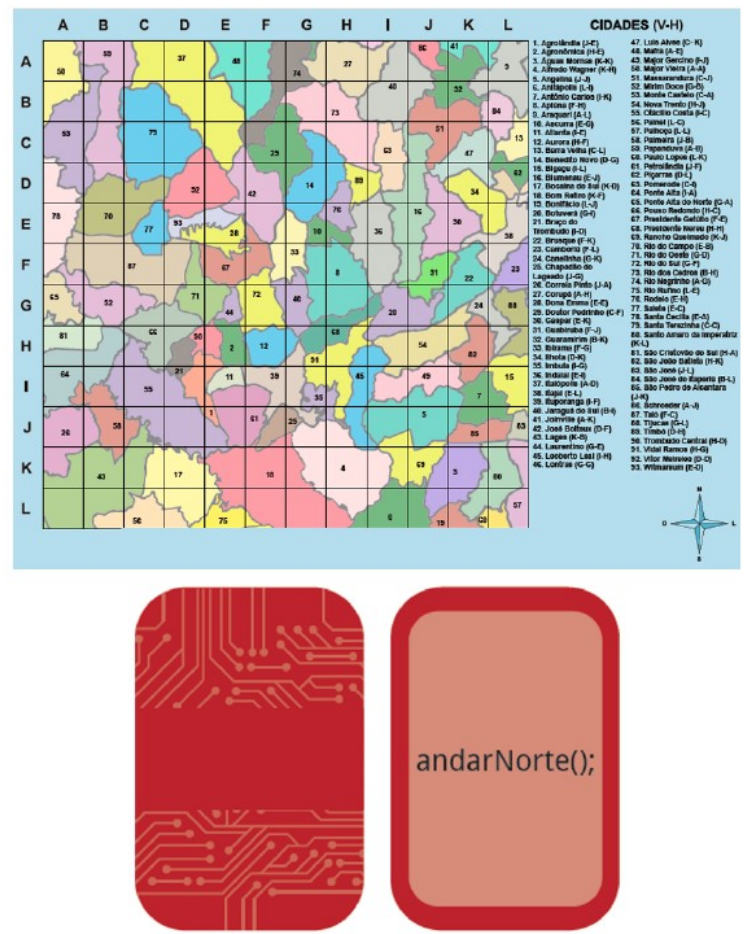

Figura 5. Jogo de tabuleiro 
VII Congresso Brasileiro de Informática na Educação (CBIE 2018)

Anais do XXIV Workshop de Informática na Escola (WIE 2018)

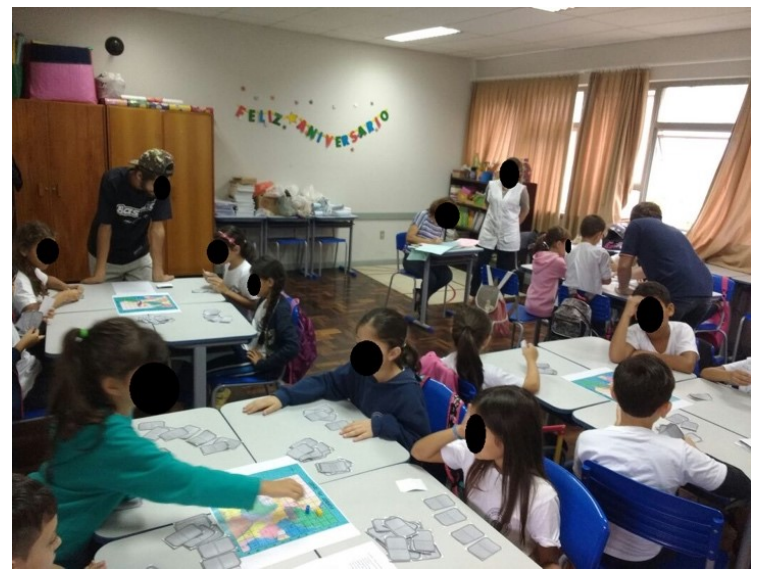

Figura 6. Atividade inicial

Todos os encontros realizados seguiram essa metodologia da pesquisa-ação, envolvendo as etapas do dianóstico até a reflexão. Depois de aproximadamente um mês de prática dessa atividade, dividida em quatro encontros, percebeu-se uma evolução em relação às sequências de passos produzidos desde o primeiro encontro. Percebeu-se que as crianças começavam a buscar o menor caminho, desviavam dos obstáculos, assim como evitavam passar duas vezes por uma mesma célula.

O segundo passo, foi introduzir o algoritmo de programação composto pelos comandos andarDireita(), andarEsquerda(), andarAcima() e andarAbaixo(), que representam os passos utilizados para resolver a atividade do tabuleiro. A prática deste algoritmo foi introduzida com o uso da ferramenta adaptada e produzida pela equipe de extensão, apresentada na seção anterior.

Durante as atividades com a plataforma computadorizada, as crianças praticavam de forma individual ou em dupla vários exercícios relacionados a labirintos, problemas matemáticos e desvio de obstáculos pelo caminho. Essa prática durou aproximadamente 5 meses, em 25 encontros de 1 hora cada. Em todos os encontros, havia entre 3 e 5 tutores de apoio para as crianças, de modo a proporcionar um aprendizado personalizado. Dessa forma, foi possível que cada criança evoluísse no exercício a medida em que finalizava a tarefa dada.

Inicialmente, houve uma diferença nítida em relação às crianças que já possuíam uma lógica mais evoluída, pois conseguiam concluir em torno de 5 exercícios por encontro, enquanto as crianças com maior dificuldade concluíam no máximo 2 exercícios. Pôde-se notar, além disso, que as crianças com maior dificuldade também tinham dificuldade na disciplina de matemática, conforme relato da professora das turmas.

Nos quatro primeiros meses de atividade, trabalhou-se somente com exercícios que envolviam a lógica sequencial. Nos primeiros dois meses, as crianças utilizavam as setas do teclado para mover seu personagem e no terceiro e quarto mês precisaram digitar o código-fonte correspondente para a solução do problema. Por fim, no último mês, introduziu-se a lógica de repetição através do comando enquanto. Em todos os momentos de exercícios, quando as crianças tinham dúvidas, os tutores a auxiliavam e explicavam individualmente de modo a proporcionar um desenvolvimento em seu aprendizado. 
VII Congresso Brasileiro de Informática na Educação (CBIE 2018)

Anais do XXIV Workshop de Informática na Escola (WIE 2018)

Antes de iniciar a lógica de repetição, com o objetivo de validar se a prática dos exercícios de programação já havia melhorado o raciocínio lógico e o pensamento computacional, aplicou-se mais uma atividade sem o uso da ferramenta. Nessa atividade, foi solicitado que cada criança escrevesse individualmente o algoritmo sequencial para três tarefas cotidianas, sendo elas: sair de sua cadeira da sala de aula e chegar até a cantina; descrever o processo matemático utilizado para dividir o número 32 por 2; e descrever os passos para tirar o caderno de sua mochila.

Ao passar as atividades para as crianças, já surgiram os questionamentos: "devo chegar até que lugar da cantina?", "O caderno deve ser colocado em cima da mesa?", "posso contar a quantidade de passos que levo para chegar até a porta?", entre outros. Essas questões foram feitas por crianças que inicialmente tinham dificuldades em raciocinar problemas considerados simples, bem como por crianças que já tinham um pensamento lógico mais desenvolvido. Dessa forma, pode-se concluir que as atividades de programação auxiliaram no desenvolvimento do pensamento computacional, pois sem a resposta para esses questionamentos, as crianças não conseguiriam concluir a atividade de forma correta. As crianças conseguiram observar que há algumas variáveis envolvidas para a resolução dos problemas e que elas precisam ser bem definidas, pois caso contrário o problema não será resolvido.

Depois dessa atividade, foram lidos para a turma alguns algoritmos produzidos por eles. Um dos algoritmos que chamou a atenção foi o relacionado a retirar o caderno da mochila e colocar sobre a mesa, sendo o seguinte: viro para trás, abro o zíper da mochila, pego o caderno e o penal, viro para frente e coloco o caderno em cima da mesa. Após a leitura deste algoritmo, a primeira pergunta feita por um aluno foi: "e onde ficou o penal?". Enfatizando a evolução do pensamento computacional, pois perceberam que o problema não havia sido concluído completamente e/ou corretamente.

\section{Resultados e trabalhos futuros}

Como resultado da pesquisa-ação, é possível evidenciar uma considerável evolução na capacidade cognitiva e no raciocínio lógico para a construção de algoritmos e solução de problemas. De acordo com o exercício mencionado na seção anterior da PesquisaAção, no início do estudo foi proposta uma atividade em que os alunos deviam descrever uma sequência de passos para concluir um objetivo. Inicialmente, o desenvolvimento desse passo a passo foi totalmente superficial e simples. Entretanto, após a aplicação da ferramenta descrita neste artigo, o mesmo exercício foi proposto, e o resultado foi significantemente melhor, pois os alunos puderam desenvolver uma sequência lógica mais elaborada, considerando diversas variáveis ao decorrer do seu algoritmo. Este resultado evidencia um impacto positivo no raciocínio lógico dos alunos envolvidos.

Relacionando as práticas aplicadas com as recomendadas pelo documento de [Raabe et al. 2017], pode-se afirmar que o presente trabalho desenvolveu o poder de abstração de experiências concretas, uma vez que a pesquisa-ação abordou problemas cotidianos, como a saída ao recreio. Nessa situação, as crianças precisaram identificar os elementos importantes para a resolução do problema, abstraindo outros fatores como a sala de aula e outros materiais que estavam na mochila que não era necessário para a atividade. Seguindo o exemplo citado, o aluno precisava descrever uma sequência de passos lógicos para sair ao recreio utilizando instruções de algoritmos para cumprir este objetivo. 
VII Congresso Brasileiro de Informática na Educação (CBIE 2018)

Anais do XXIV Workshop de Informática na Escola (WIE 2018)

Como, primeiramente o aluno levanta da cadeira, em seguida guarda o caderno, fecha a mochila e executa os passos necessários para se movimentar até o pátio.

Com relação à prática do jogo, pode-se perceber uma evolução progressiva no decorrer das aulas de laboratório integradas às aulas introdutórias no tabuleiro. Os alunos demonstravam um maior entendimento da lógica computacional.

Como trabalhos futuros, pretende-se aplicar o projeto em outras escolas e com outras séries de ensino fundamental, com o objetivo de afirmar a contribuição deste trabalho. Além disso, tem-se a intenção de disponibilizar um material de modo que pais, crianças e professores possam utilizar o jogo produzido para a educação de suas crianças.

\section{Referências}

Davison, R. M., Martinsons, M. G., and Koch, N. (2004). Principles of canonical action research. Information Systems Journal, 14:65-86.

Raabe, A. L. A., Zorzo, A. F., Frango, I., Ribeiro, L., Granville, L. Z., Salgado, L., da Cruz, M. J. K., adn Simone André Costa Cavalheiro, N. B., and Fortes, S. (2017). Computação na educação básica. In de Computação, S. B., editor, Referenciais de Formação em Computação: Educação Básica, pages 1-9.

Schlogl, L. E., de Oliveira, G. C., Giovanella, G. C., Bizon, A., Santos, B., Kruger, N., Bursoni, P., Neumann, C. B., Huber, E. E., de Araújo, L. P., Mattos, M. M., Mattos, M. M., Zucco, F. D., Zendron, K., and Hein, N. (2017). Ensino do pensamento computacional na educação básica. Revista de Sistemas e Computação (RSC), 7(2):304-322.

Scolari, A. T. and Bernardi, G. (2007). O desenvolvimento do raciocínio lógico através de objetos de aprendizagem. Revista Renote Novas Tecnologias na Educação, 5(37):110 . 